\title{
Food Intake, Infectious Diseases and Its Association with Wasting Status among Children, a Community- Based Cross-Sectional Study
}

\author{
Azrimaidaliza $^{1}$, Hafifatul Aulia Rahmi ${ }^{2}$, Nurul Prativa ${ }^{3}$ \\ \{azrimaidaliza@ph.unand.ac.id ${ }^{1}$, hafifatul@ph.unand.ac.id ${ }^{2}$, nurulprativa7@gmail.com ${ }^{3}$ \} \\ Nutrition Department, Andalas University, Padang, Indonesia ${ }^{1,2,3}$
}

\begin{abstract}
Developing countries, including Indonesia, are still faced with wasted prevalence among under-five children. The studies aim to examine food intake and infectious diseases as the determinant of wasted prevalence among children. The crosssectional study was undertaken among under-five children in two selected health center area in Padang city. Data was collected through the standardized questionnaires. There is $10.0 \%$ of children with wasted nutritional status. The result showed that carbohydrate intake and diarrhea disease are both the dominant factors that have an association with wasted status among children under five years ( $p$-value $=0.015 ; \quad P O R=5.713$; $95 \% \mathrm{CI}=1.395-23.403$ ). We suggest mother give children healthy food which balances nutrient regarding their needs, especially carbohydrate rich-foods as the main source of energy and create a healthy environment to decrease infectious diseases risk for the optimal growth and development.
\end{abstract}

Keywords: food intake, infectious diseases, wasted status, under-five aged children

\section{Introduction}

Malnutrition is still a big problem in the world, particularly in developing countries such as Indonesia, and it is the major underlying cause of mortality and morbidity among children under five years [1]. As we know that the long-term impact of malnutrition on people's lives, most notably in health status, education, and productivity. Moreover, it can also affect the human capital of the country [2].

Undernutrition is one of the malnutrition terms, which is included wasting, underweight, and stunting [3]. Focus on wasting, regarding the term of acute malnutrition is defined as weight for height with z-score below minus two standard deviations from the median weight for height of the standard reference population [4]. World Health Organization (WHO) year 2018 reported that 52 million children under five years of age are wasted, and 17 million are severely wasted worldwide. In Indonesia, based on basic health survey or Riskesdas informed that wasting prevalence was $12,1 \%$ in the year 2013, then decreased become $10,2 \%$ year 2018 . Specifically, in West Sumatera Province, wasting prevalence was $4.1 \%$ year 2016 and increased become $10.1 \%$ year 2017 [5].

Under-five children as one of the vulnerable groups need a higher food intake for optimal growth and development compared with another aged group. The previous studies have reported several factors that have an association with nutritional status among children under five years. However, the findings are less consistent, and the difference of the dominant factor 
is related to nutritional status. The United Nations Children Fund (UNICEF) informed that insufficient food intake and recurrent infectious diseases have a direct association with the undernutrition status among children [6]. Although the factors of wasting vary from country to country, food security, feeding pattern, hygiene sanitation, health care, nutrition knowledge, economic status, and parental characteristic are considered as the indirect factors which are also the important risk factors of wasting among children $[7,8,9,10,11]$

The study aims to determine the food intake and infectious diseases that were associated with the wasting status among children under five years in Padang city.

\section{Method}

This study used a cross-sectional design study to examine the dominant factor which was associated with the wasting status among children under five years. This study located in the two selected health center areas in Padang city, the western of Indonesia. The background of choosing this health center was the highest of undernutrition prevalence than other health center areas. The study was conducted from March to June year 2019.

All children from 12 months until 59 months aged in Air Dingin Health Centre and Anak Air Health Centre, Padang city, were the study population in this study. The sample size was counted by Lameshow formula for the population with two proportion:

$$
\mathrm{n}=\frac{\left\{z_{1-\alpha / 2} \sqrt{2 P(1-F)}+z_{1-\beta} \sqrt{P_{1}\left(1-P_{1}\right)+P_{2}\left(1-P_{2}\right)}\right\}^{2}}{\left(P_{1}-P_{2}\right)^{2}}
$$

A total of 120 under-five children was included as the sample of the study and the child's mother as the respondent of the study, which was taken by simple random sampling. The list of children aged 12 to 59 years was collected from health institutions. Then, the computer program will process the list and sampling the data.

The intensive training, including anthropometric measurement, was held for the data collector to prepare the survey. The experienced enumerators collected the data. It is due to the perception of the research objective strategy to increase the quality of the data.

\section{Result}

A total of 120 children under five years has participated in the study. The result showed that $10.0 \%$ children under five years were wasting status. The study indicated that the risk of wasting decreases with age. Children age between 12-23 months (14.7\%) were higher to be wasted compared with children age between 24-35 months (10.3\%), 36-47 months (9.4\%), and $48-59$ months $(4.0 \%)$, respectively. Moreover, male children were higher being wasting $(11.7 \%)$ than female children $(8.3 \%)$.

The mean of food intake, namely energy, carbohydrate, fat, and protein intake among children under five years according to nutritional status, were presented in Table 1. 
Table 1. The mean of food intake based on nutritional status among children under five years

\begin{tabular}{lcccc}
\hline \multicolumn{1}{c}{$\begin{array}{c}\text { Food Intake/ } \\
\text { Nutritional Status }\end{array}$} & $\mathrm{N}$ & Mean & $\begin{array}{c}\text { Standard } \\
\text { Deviation }\end{array}$ & P-value $^{*}$ \\
\hline $\begin{array}{l}\text { Energy intake (calorie) } \\
\text { Wasting }\end{array}$ & 12 & 846.87 & 128.02 & 0.008 \\
Normal & 108 & 1077.7 & 292.59 & \\
Carbohydrate intake (gram) & 12 & 1299.5 & 38.26 & 0.039 \\
Wasting & 108 & 1737.1 & 184.09 & \\
Normal & 12 & 34.79 & 10.59 & 0.053 \\
Fat intake (gram) & 108 & 43.30 & 14.61 & \\
Wasting & 12 & & & \\
Normal & 108 & 20.89 & 4.73 & 0.038 \\
Protein intake (gram) & 25.67 & 7.69 & \\
$\quad$ Wasting & & & \\
Normal & & & \\
\hline
\end{tabular}

Overall, the mean of food intake was lower among wasted children than normal children, and it was statistically significant the difference in food intake according to the nutritional status of children under five years (Table 1). After we compared with Recommended Dietary Allowances (RD) in Indonesia, it was found that wasted children consume a source of energy, carbohydrate, fat, and protein less than $80 \%$ of RDA (range $70 \%$ until $77 \%$ of RDA). However, normal children consumed food more than $80 \%$ (range $83 \%$ until $88 \%$ RDA).

Moreover, food intake was categorized into two groups (less or lack of food intake and normal food intake) regarding RDA in Indonesia. Then, bivariate analysis using chi-square test was done to examine the association between food intake and infectious diseases with nutritional status based on weight for height indices. The result identified that food intake, such as energy intake, carbohydrate intake, fat intake, and protein intake, have an association with wasting status among children under five years. It also relates with infectious diseases such as diarrhea and acute respiratory infections disease ( $\mathrm{p}$-value $<0.05$ ). The result showed that the percentage of wasting was higher among children with a lack of food intake (energy intake, carbohydrate intake, fat intake, and protein intake) and had infectious diseases than children with enough food intake and had no contagious diseases. The result could be seen in Table 2 below.

Table 2. Distribution wasting status based on food intake and infectious diseases

\begin{tabular}{|c|c|c|c|c|c|c|}
\hline \multirow{2}{*}{ Variables } & \multicolumn{2}{|c|}{ Wasting } & \multicolumn{2}{|c|}{ Normal } & \multirow{2}{*}{ p-value $\left.{ }^{*}\right)$} & \multirow{2}{*}{ POR } \\
\hline & $\mathrm{f}$ & $\%$ & $\mathrm{f}$ & $\%$ & & \\
\hline \multicolumn{7}{|l|}{ Food intake } \\
\hline \multicolumn{7}{|l|}{ 1. Energy } \\
\hline Less & 10 & 18.2 & 45 & 81.8 & \multirow{2}{*}{0.012} & 7.000 \\
\hline Enough & 2 & 3.1 & 63 & 96.9 & & $(1.463-33.500)$ \\
\hline \multicolumn{7}{|l|}{ 2. Carbohydrate } \\
\hline Less & 9 & 17.6 & 42 & 82.4 & \multirow{2}{*}{0.028} & 4.714 \\
\hline Enough & 3 & 4.3 & 66 & 95.7 & & $(1.207-18.418)$ \\
\hline \multicolumn{7}{|l|}{ 3. Protein } \\
\hline Less & 9 & 18.0 & 41 & 82.0 & \multirow{2}{*}{0.027} & 4.902 \\
\hline Enough & 3 & 4.3 & 67 & 95.7 & & $(1.254-19.162)$ \\
\hline \multicolumn{7}{|l|}{ 4. Fat } \\
\hline Less & 10 & 20.0 & 40 & 80.0 & \multirow{2}{*}{0.004} & 8.500 \\
\hline Enough & 2 & 2.9 & 68 & 97.1 & & $(1.773-40.759)$ \\
\hline
\end{tabular}




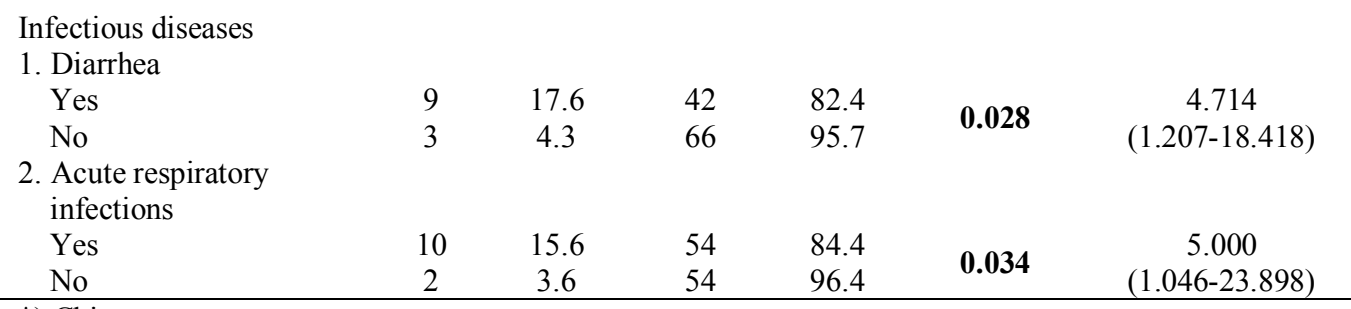

*) Chi-square test

In further analysis with multiple logistic regression was done to examine the dominant factor of wasting status among children under five years. Before the analysis of food intake, infectious disease, and nutritional status, we examined the dominant factor of wasting status based on food intake. From the result, protein intake was the dominant factor from food which related to nutritional status based on weight for height index $(p=0.007 ; \mathrm{OR}=8.500$; $95 \% \mathrm{CI}=1.773$ to 40.759 ). But after analysis of all factors, both food intake, and infectious disease, regarding wasting status, we found that lack of carbohydrate intake and diarrhea diseases were the dominant factors of wasting status among children under five years. Lack of carbohydrate intake and history of infectious diseases have a strong association with wasting status. Moreover, this finding noted that children under five years with a lack of carbohydrate intake and had a history of diarrhea disease were 5.713 times more likely to be wasted than children under five years with enough carbohydrate intake and no history of diarrhea disease ( $\mathrm{p}$ value $=0.015 ; \mathrm{POR}=5.713 ; 95 \% \mathrm{CI}=1.395-23.403$ ). The result of the regression logistics could be seen in Table 3 .

Table 3. Multivariate analysis according to nutritional status among children under five years

\begin{tabular}{lccc}
\hline Multivariate analysis & POR & $95 \%$ CI & P-value ${ }^{*}$ \\
\hline First model & & & \\
Energy intake & 3.679 & $0.654-20.691$ & 0.139 \\
Carbohydrate intake & 3.209 & $0.548-18.792$ & 0.196 \\
Fat intake & 2.229 & $0.497-10.009$ & 0.295 \\
Protein intake & 1.557 & $0.196-12.376$ & 0.675 \\
Diarrhea disease & 3.794 & $0.821-17.529$ & 0.088 \\
Acute respiratory infectious & 2.113 & $0.342-13.055$ & 0.421 \\
Last model & & & \\
Carbohydrate intake & 5.713 & $1.395-23.403$ & 0.015 \\
Diarrhea disease & 5.713 & $1.395-23.403$ & 0.015 \\
\hline
\end{tabular}

\section{Discussion}

This study found that the prevalence of wasting in the 12-59 months old children was $10.0 \%$. This result is the same as the Indonesian national data year 2018. However, this finding is a lower prevalence than Habtamu Fekadu finding the year 2013 in Ethiopia and Amel Abdalrhim Sulaiman study year 2018 in North Sudan who got higher prevalence than 
this study were about $12.0 \%$ and $21.4 \%$, respectively.[12,9] But, this data got a higher prevalence than Beatrice Olak study year 2011 in an informal urban settlement in Nairobi, Kenya, and Idowu study year 2016 in Lagos State, Nigeria, were $2.6 \%$ and 5.3\%, respectively.[13]

This finding identified that the wasted condition is a higher percentage among children at a young age (12-23 months) than older age $(>23-<60$ months). It looks like the prevalence of wasting was decrease according to age. Moreover, male children are a higher percentage to be likely wasting than female children. Habtamu Fekadu also noted the same result et al. (2014), which found the wasting status was more happened among children at a younger age than older age because after six months. Children were not practicing exclusive breastfeeding and given additional food besides breastfeeding, so the probability of getting wasting was high $[12,9]$. Furthermore, male children have high rates of wasting status. It might have happened because male children are frequently active, spent more time outside the home than female children. This situation was easy for children to expose to an unhealthy environment. Besides, the timing and type of complementary food introduced in the infant's diet were also contributed to the nutritional status of under-five children.[13]

The study highlights the difference in the mean of food intake according to the nutritional status of under-five children. The mean of food intake in the study was lower among wasted children than normal children and not met their needs for food intake (less than $80 \%$ RDA). According to RDA in Indonesia year 2014, children on age more than 12 months until 36 months should consume food source of energy, carbohydrate, fat, and protein about 1125 calorie per day, 155 grams, 44 grams, 26 grams, respectively and for children on age more than 36 months until 59 months should consume 1600 calories, 220 grams, 62 grams, and 36 respectively.

From the bivariate analysis, all food intake and infectious diseases were associated with wasting conditions among children under five years. Children with wasting status are a higher percentage of lack of food intake and had a history of infectious diseases than normal food intake and no history of infectious diseases. However, the lack of carbohydrate intake and had a history of diarrhea disease were both the dominant factor and strongly associated with wasting condition among children under five years after this data was analyzed by multivariate analysis. It is important to note that a high intake of carbohydrate-rich food should consume by children according to their needs to give energy for activities and have a lower risk of infectious diseases [14]. It might be under five children aged 12 until 23 months in the present study who had not to consume an adequate food intake, especially carbohydrate intake after being introduced to solid food, semi-solid or soft food after exclusive breastfeeding period or too early be introduced complement breastfeeding.

\section{Conclusion}

The prevalence of wasting under-five children was $10.0 \%$. This wasting condition was found to be the result of carbohydrate intake and diarrhea disease as the dominant factors. Therefore, a community based nutritional promotion program and create a healthy environment are essential to combat this problem. Information about healthy and varied food for children according to their needs, specifically consume a good source of carbohydrate nutrients, should be delivered routinely by health professionals to the mothers. Besides, create 
hygiene sanitation and a healthy environment to decrease the risk of infectious disease among children under five years should be done in the community.

\section{References}

[1] UNICEF. 2016. The state of the world's children in 2016, a fair chance for every child. https://www.unicef.org/publications/files/UNICEF_SOWC_2016.pdf.

[2] Beruk Berhanu Desalegn, Christine Lambert, Simon Riedel, Tegene Negese, and Hans Konrad Biesalski. 2019. Feeding Practices and Undernutrition in 6-23-Month-Old Children of Orthodox Christian Mothers in Rural Tigray, Ethiopia: Longitudinal Study. Nutrients 2019, 11, 1382 of 15

[3] World Health Organization. 2018. Malnutrition. Access at https://www.who.int/news-room/factsheets/detail/malnutrition.

[4] UNICEF. 2011. The global average rate of children under five years of age who are underweight was $16 \%$.

[5] Kemenkes RI. Riset Kesehatan Dasar. Jakarta: Badan Penelitian dan Pengembangan Kesehatan; 2018. http://labdata.litbang.depkes.go.id/riset-badan-litbangkes/ menu-riskesnas/menuriskesdas/426-rkd-2018

[6] UNICEF. 2013. Improving child nutrition. https://www.unicef.org/gambia /Improving_Child_Nutrition_-_the_achievable_imperative_for_global_progress.pdf

[7] Michael Boah, Fusta Azupogo, Daniel Adjei Amporfro, Linda Anutua Abada. 2019. The epidemiology of undernutrition and its determinants in children under five years in Ghana. Plos one, July 31, 2019. Access at https://journals.plos.org/plosone/article?id=10.1371/journal.pone.021966

[8] Alphonse Nshimyiryo, et al, 2019. Risk factors for stunting among children under five years: a cross-sectional population-based study in Rwanda using the 2015 Demographic and Health Survey. BMC Public Healthvolume 19, Article number: 175 (2019). Access at https://bmcpublichealth.biomedcentral.com/articles/10.1186/s12889-019-6504-z.

[9] Amel Abdalrhim Sulaiman, et al. 2018. Prevalence and determinants of under nutrition among children under 5-year-old in rural areas: A cross-sectional survey in North Sudan. J Family Med Prim Care. 2018 Jan-Feb; 7(1): 104-110. Access at https://www.ncbi.nlm.nih.gov/pmc/articles/PMC5958549/.

[10] Edris M, Derso T and Abebe Z. 2018. Undernutrition and associated factors among children aged 6-59 months living in slum areas of Gondar city, northwest Ethiopia: a cross-sectional study. Pediatric Health, Medicine and Therapeutics Journal, Volume 9. Access at https://www.dovepress.com/undernutrition-and-associated-factors-among-children-aged-6ndash59mon-peer-reviewed-fulltext-article-PHMT.

[11] Elham Kavosi, et al. 2014. Prevalence and determinants of under-nutrition among children under six: a cross-sectional survey in Fars province, Iran. Int J Health Policy Manag. 2014 Jul; 3(2): $71-$ 76. Access at https://www.ncbi.nlm.nih.gov/pmc/articles/PMC4122078/.

[12] Habtamu Fekadu, Alemu Adeba, Sileshi Garoma and Wondu Garoma. 2014. Prevalence's of Wasting and its Associated Factors of Children among 6-59 months Age in Guto Gida District, Oromia Regional State, Ethiopia. J Food Process Technol 2014, 5:1

[13] Beatrice Olak, et al. 2011. Nutritional Status of Under-five Children Living in an Informal Urban Settlement in Nairobi, Kenya. J Health Popul Nutr. 2011 Aug; 29(4): 357-363.

[14] Idowu O. Senbanjo, Ibiyemi O. Olayiwola and Wasiu A. O. Afolabi. Dietary practices and nutritional status of under-five children in rural and urban communities of Lagos State, Nigeria. Niger Med J. 2016 Nov-Dec; 57(6): 307-313. https://www.ncbi.nlm.nih.gov/pmc/articles/PMC5126741/. 